Freshwater Ascomvcetes: Minutisphaera (Dothideomvcetes) revisited, including one new species from Japan

By: Huzefa A. Raja, Nicholas H. Oberlies, Mario Figueroa, Kazuaki Tanaka, Kazuyuki Hirayama, Akira Hashimoto, Andrew N. Miller, Steven E. Zelski, Carol A. Shearer

Raja H.A., Tanaka K., Hirayama K., Hashimoto A., Oberlies N.H., Figueroa M., Miller A.N., Zelski S.E., Shearer C.A. 2013. Freshwater Ascomycetes: Minutisphaera (Dothideomycetes) revisited, including one new species from Japan. Mycologia 105: 959-976.

Made available courtesy of The Mycological Society of America: http://dx.doi.org/10.3852/12-313

***:(C) The Mycological Society of America. Reprinted with permission. No further reproduction is authorized without written permission from The Mycological Society of America. This version of the document is not the version of record. Figures and/or pictures may be missing from this format of the document. ***

\begin{abstract}
:
During investigations of freshwater ascomycetes we found one interesting taxon from Aomori (Japan), as well as three additional taxa from North Carolina (USA), which were morphologically similar to Minutisphaera, a recently described freshwater fungus in the Dothideomycetes. The ascomata of all the collections bore dark hair-like structures around the ostiolar region, obovoid to obclavate bitunicate asci, and one to three septate hyaline to brown ascospores with a sheath (in material from Japan), and with both sheath and appendages (in material from the USA). The apothecial ascomata of these taxa, however, differ from those of the type species of the genus, which are perithecial. Two collections of Minutisphaera-like fungi from the USA were morphologically quite similar but differed in ascospore size. To assess the phylogenetic affinities of Minutisphaera-like taxa with the type species, M. fimbriatispora, we sequenced $18 \mathrm{~S}$ and $28 \mathrm{~S}$ nrDNA of five newly collected strains of Minutisphaera. We also sequenced the nrDNA for the entire internal transcribed spacer region of 10 strains to assess interspecific and intraspecific variation with M. fimbriatispora. Additionally we examined the secondary metabolite profiles of two strains from USA. Based on maximum likelihood and Bayesian analyses of combined $18 \mathrm{~S}$ and $28 \mathrm{~S}$, and separate ITS sequences, as well as examination of morphology, we describe and illustrate a new species, M. japonica. One collection from North Carolina is confirmed as M. fimbriatispora, while two other collections are Minutisphaera-like fungi that had a number of similar diagnostic morphological characters but differed only slightly in ascospore sizes. The phylogeny inferred from the internal transcribed spacer region suggested that two out of the three North Carolina collections may be novel and perhaps cryptic species within Minutisphaera. Organic extracts of Minutisphaera from USA, M. fimbriatispora (G1551) and Minutisphaera-like taxon (G156-1), revealed the presence of palmitic acid and (E)hexadec-9-en-1-ol as major chemical constituents. We discuss the placement of the Minutisphaera clade within the Dothideomycetes. The description of the genus Minutisphaera is emended to accommodate M. japonica within Minutisphaera.
\end{abstract}

Keywords: aquatic $\mid$ minute fungi $\mid$ submerged wood $\mid$ systematics 
Article:

$* * *$ Note: Full text of article below 
Mycologia, 105(4), 2013, pp. 959-976. DOI: 10.3852/12-313

\# 2013 by The Mycological Society of America, Lawrence, KS 66044-8897

\section{Freshwater Ascomycetes: Minutisphaera (Dothideomycetes) revisited, including one new species from Japan}

Huzefa A. Raja ${ }^{1}$

Nicholas H. Oberlies

Mario Figueroa

Department of Chemistry and Biochemistry, University of North Carolina at Greensboro, Greensboro, North Carolina 27412

Kazuaki Tanaka

Kazuyuki Hirayama

Akira Hashimoto

Faculty of Agriculture and Life Sciences, Hirosaki University, Bunkyo-cho, Hiroskaki, Aomori 036-8561, Japan

Andrew N. Miller Illinois Natural History Survey, University of Illinois, Champaign, Illinois 61820

Steven E. Zelski

Carol A. Shearer

Department of Plant Biology, University of Illinois, Urbana, Illinois 61801

Abstract: During investigations of freshwater ascomycetes we found one interesting taxon from Aomori (Japan), as well as three additional taxa from North Carolina (USA), which were morphologically similar to Minutisphaera, a recently described freshwater fungus in the Dothideomycetes. The ascomata of all the collections bore dark hair-like structures around the ostiolar region, obovoid to obclavate bitunicate asci, and one to three septate hyaline to brown ascospores with a sheath (in material from Japan), and with both sheath and appendages (in material from the USA). The apothecial ascomata of these taxa, however, differ from those of the type species of the genus, which are perithecial. Two collections of Minutisphaera-like fungi from the USA were morphologically quite similar but differed in ascospore size. To assess the phylogenetic affinities of Minutisphaeralike taxa with the type species, $M$. fimbriatispora, we sequenced $18 \mathrm{~S}$ and $28 \mathrm{~S}$ nrDNA of five newly collected strains of Minutisphaera. We also sequenced the nrDNA for the entire internal transcribed spacer region of 10 strains to assess interspecific and intraspecific variation with $M$. fimbriatispora. Additionally we examined the secondary metabolite profiles of two strains from USA. Based on maximum

Submitted 31 Aug 2012; accepted for publication 17 Dec 2012.

${ }^{1}$ Corresponding author. E-mail: haraja@uncg.edu likelihood and Bayesian analyses of combined 18S and 28S, and separate ITS sequences, as well as examination of morphology, we describe and illustrate a new species, $M$. japonica. One collection from North Carolina is confirmed as $M$. fimbriatispora, while two other collections are Minutisphaera-like fungi that had a number of similar diagnostic morphological characters but differed only slightly in ascospore sizes. The phylogeny inferred from the internal transcribed spacer region suggested that two out of the three North Carolina collections may be novel and perhaps cryptic species within Minutisphaera. Organic extracts of Minutisphaera from USA, M. fimbriatispora (G155-1) and Minutisphaera-like taxon (G156-1), revealed the presence of palmitic acid and (E)-hexadec-9-en-1-ol as major chemical constituents. We discuss the placement of the Minutisphaera clade within the Dothideomycetes. The description of the genus Minutisphaera is emended to accommodate $M$. japonica within Minutisphaera.

Key words: Aquatic, minute fungi, submerged wood, systematics

\section{INTRODUCTION}

The freshwater Dothideomycetes is an ecological group of fungi (Shearer et al. 2009) that currently comprise approximately 195 species, which constitute about $32 \%$ of the currently known freshwater ascomycetes (Shearer and Raja 2012). Most species of freshwater Dothideomycetes belong in the Pleosporales (Zhang et al. 2012) or Jahnulales (Pang et al. 2002, Campbell et al. 2007, Suetrong et al. 2011), although few taxa have affinities to the Capnodiales and Tubeufiaceae (Shearer et al. 2009).

Based on evaluation of morphological characters and multigene molecular phylogenetic studies, several new families have been assigned recently to the freshwater Dothideomycetes. These families include Aliquandostipitaceae (Inderbitzin et al. 2001), Amniculicolaceae (Zhang et al. 2008, 2009a, b), Lentitheciaceae (Zhang et al. 2009b, c), Lindgomycetaceae (Hirayama et al. 2010), Morosphaeriaceae (Suetrong et al. 2009, Boonmee et al. 2012) and Natipusillaceae (Raja et al. 2012). Although molecular sequence data has provided phylogenetic placements for numerous freshwater Dothideomycetes, a number of Dothideomycetes from freshwater habitats occur as singletons and remain incertae sedis (Shearer et al. 2009). 
Minutisphaera Shearer, A.N. Mill. \& Ferrer, typified by $M$. fimbriatispora Shearer, A.N. Mill. \& Ferrer, is a recently described species from submerged wood in freshwater habitats from USA (Ferrer et al. 2011). It is characterized by small globose to subglobose ascomata with dark brown to black hairs around the ostiole, fissitunicate, oblong to obclavate, eightspored asci, and one-septate, multiguttulate, hyaline to pale brown ascospores equipped with a gelatinous sheath and numerous filamentous appendages radiating around the spore at the mid-septum. Minutisphaera currently is placed in the Dothideomycetes based on morphological as well as nuclear ribosomal sequence data, but its relationship with other taxa within the Dothideomycetes remains unresolved.

During ongoing investigations of freshwater ascomycetes in the USA (Raja et al. 2011b) and Japan (Hirayama et al. 2010), we found interesting taxa from both Aomori (Japan) and North Carolina (USA), which were morphologically similar to Minutisphaera. These taxa have dark hair-like structures around the ostiolar region, broadly shaped bitunicate asci, and 1-3-septate, hyaline to brown ascospores with a sheath in material from Japan, and with both a sheath and appendages in material from USA. The ascomata of these taxa, however, appeared more apothecioid than those of the type species of the genus. In addition, collections of Minutisphaera-like fungi from USA showed variation in ascospore size. For example, the ascospores of G155-1 were more similar to those reported for M. fimbriatispora but the ascospores of G156-1 and G156-2 were comparatively smaller than those of $M$. fimbriatispora (Ferrer et al. 2011). Whether these size variations are intraspecific or result from cryptic speciation and therefore interspecific within Minutisphaera is unknown at this time.

The goal of the present study, therefore, was to understand the phylogenetic relationships of Minutisphaera-like taxa collected from Japan and North Carolina (USA) with the original collections of $M$. fimbriatispora and within the Dothideomycetes. To address this goal, we undertook a molecular phylogenetic study using partial $18 \mathrm{~S}$ small subunit nrDNA (SSU) and 28S large subunit nrDNA (LSU). To better understand species boundaries of our collections within Minutisphaera, we conducted phylogenetic analyses based on ITS sequences and compared taxa based on morphological characteristics. In addition, as part of ongoing investigations of chemical mycology of freshwater fungi, we screened two strains of Minutisphaera from USA (G155-1 and G156-1) for secondary metabolite production because these fungi had not been investigated previously for chemical constituents.

\section{MATERIALS AND METHODS}

Morphological studies and fungal isolates.-Methods of morphological observation are described by Tanaka et al. (2009). For ascospore septum position, the decimal system (Shoemaker 1984) was used. Single ascospore cultures were obtained according to Shearer et al. (2004). For the Japanese collections, ascomata formation was induced by placing a small piece of mycelial culture on rice straw agar (RSA; Tanaka and Harada 2003). Colony colors on potatodextrose agar (PDA; Difco), cornmeal agar (CMA; Difco) and weak oatmeal agar (wOA; $15 \mathrm{~g}$ Difco oatmeal agar, $6 \mathrm{~g}$ agar, 1 L water; Zhao and Shamoun 2006) were characterized using Rayner (1970). Fungal cultures obtained from Japan were deposited at the Japan Collection of Microorganisms (JCM) and the National Institute of Agrobiological Sciences (MAFF). Cultures from USA were deposited in the Department of Plant Biology Culture Collection at the University of Illinois and Department of Chemistry and Biochemistry Culture Collection at the University of North Carolina at Greensboro (UNCG).

DNA extraction and amplification.- Detailed protocols for DNA extraction and PCR amplification were described by Hirayama et al. (2010). DNA from mycelia was extracted with the ISOPLANT Kit (Nippon Gene Co., Tokyo, Japan) according to the manufacturer's instructions. Partial SSU and LSU and the complete ITS region of nrDNA were amplified with three primer sets, NS1-NS4 (White et al. 1990), LROR-LR7 (Rehner and Samuels 1994) and ITS1/ 1F-ITS4 (White et al. 1990, Gardes and Bruns 1993). Sequences were assembled with Sequencher 4.9 (Gene Codes Corp.), optimized by eye and manually corrected when necessary.

Taxon sampling and phylogenetic analyses.-Four datasets were assembled for phylogenetic analyses: (i) a SSU dataset that consisted of 80 taxa; (ii) an LSU dataset consisting of mostly the same taxa as in the SSU dataset; (iii) a combined 83 taxa SSU and LSU dataset; and (iv) an ITS dataset with 10 strains of Minutisphaera spp. to assess interspecific and intraspecific relationships among members of the genus. For the SSU and LSU datasets, we sampled taxa from the major orders of the Pleosporomycetidae and Dothideomycetidae currently included in the Dothideomycetes (Schoch et al. 2009). Taxa included in the present study were obtained from a study on the molecular phylogeny of freshwater Dothideomycetes (Shearer et al. 2009), as well as other studies on the phylogenetic relationships among dothideomyceteous fungi (Wu et al. 2011, Zhang et al. 2012). We also included members of the Patellariales and other apothecial dothideomycete members such as Catinella olivacea (Batsch) Boudier to test whether Minutisphaera-like fungi share phylogenetic affinities with the apothecial dothideomycetous fungi. In addition, we included sequences of the Natipusillaceae to assess the phylogenetic affinities of Minutisphaera spp. with Natipusilla spp. because both these freshwater genera possess minute ascomata with bitunicate asci and their ascospores are equipped with gelatinous appendages. Members of the Arthoniomycetes were used as outgroup taxa (Schoch et al. 2009). Alignments were 
generated according to Raja et al. (2011a), and subsequently ambiguous regions, gaps and introns were excluded from the final alignment with Gblocks (Castresana 2000, Talavera and Castresana 2007) via the default parameters. We manually deleted a portion of the nucleotides from the 59 and 39 ends due to missing data in most taxa.

Maximum likelihood (ML) analyses were performed on the separate and combined datasets. We used jModeltest (Posada 2008) (with 88 possible evolutionary models) to obtain the best-fit model of nucleotide evolution for each dataset. The Akaike information criterion (AIC) (Posada and Buckley 2004) as implemented in jModeltest selected the $\operatorname{TrN}+\mathrm{I}+\mathrm{G}$ model for the SSU dataset, the TIM3+G model for the LSU dataset, the TrN+I+G model for the combined SSU and LSU dataset, and the TrNef+I model for the ITS dataset. First, we ran separate ML analyses on the individual SSU and LSU datasets using PHYML (Guindon and Gascuel 2003) with 1000 ML bootstrap replicates with a combined nearest neighbor interchange (NNI) and subtree pruning and regrafting (SPR) tree search option in effect. We evaluated bootstrap support (BS) values obtained for the individual SSU and LSU phylogenies for conflict by comparing clades with BS \$70\% (Wiens 1998). Because the topology of the clades obtained in the separate analyses did not show conflicting results, we consequently concatenated the two datasets and performed a ML analysis using PHYML with the same parameters as above with $1000 \mathrm{ML}$ bootstrap replicates to assess clade support (Felsenstein 1985). In addition to the PHYML analysis, we also ran a randomized accelerated maximum likelihood analysis with RAxML 7.0.4 (Stamatakis et al. 2008) on the combined SSU and LSU dataset on the CIPRES Portal 2.0 (Miller et al. 2010) with the default rapid hill-climbing algorithm and GTR model employing 1000 fast bootstrap searches. Clades that received a BS $\$ 70 \%$ were considered significant and robustly supported (Hillis and Bull 1993).

We then ran Bayesian analyses on the combined SSU and LSU dataset and the ITS dataset with MrBayes 3.1.2 (Huelsenbeck and Ronquist 2001, 2005) to evaluate clade support by implementing the $\operatorname{TrN}+\mathrm{I}+\mathrm{G}$ model for the combined SSU and LSU dataset and TrNef+I model for the ITS dataset. Constant characters were included, and 10000000 generations with trees sampled every 1000 generations were run, resulting in 10000 total trees. The first 1000 trees that extended beyond the burn-in phase in each analysis were discarded, and the remaining 9000 trees were used to calculate the posterior probability (PP) for each clade. The consensus of the trees was viewed in PAUP $4.0 \mathrm{~b} 10$ (Swofford 2002). The Bayesian analysis was run twice starting from a different random tree each time to ensure that trees from the same tree space were being sampled. The sequences generated in this study and the alignments used in combined SSU and LSU and ITS phylogenetic analyses were deposited respectively in GenBank (TABLES I, II) and in TreeBASE (www.treebase.org, submission 13647).

Fermentation, extraction and isolation.-Fresh cultures of G155-1a and G156-1 were grown on malt-extract slants, and a piece of agar culture was transferred to a medium containing $2 \%$ soy peptone, $2 \%$ dextrose and $1 \%$ yeast extract (YESD media). After incubation (1 wk) at $22 \mathrm{C}$ with agitation, the cultures were used to inoculate $50 \mathrm{~mL}$ rice medium prepared with $25 \mathrm{~g}$ rice with $35 \mathrm{~mL} \mathrm{H}_{2} \mathrm{O}$ in a $250 \mathrm{~mL}$ Erlenmeyer flask. This was incubated at $22 \mathrm{C}$ until the cultures showed good growth (approximately $2 \mathrm{wk}$ ). To each culture was added $150 \mathrm{~mL} 1: 1 \mathrm{MeOH}-\mathrm{CHCl}_{3}$. The mixture was shaken $16 \mathrm{~h}$ then filtered, and the solvent was evaporated. Each extract was defatted by stirring vigorously $1 \mathrm{~h}$ in a mixture of $25 \mathrm{~mL} \mathrm{MeOH}, 25 \mathrm{~mL} \mathrm{CH}_{3} \mathrm{CN}$ and $50 \mathrm{~mL}$ hexane, then partitioned in a separatory funnel. The bottom layer was collected and evaporated. Each defatted extract (17.25 and $15.84 \mathrm{mg}$ for G155-1a and G156-1 respectively) was purified on semipreparative HPLC over a Phenomenex Gemini-NX C18 (5 mm; $250310 \mathrm{~mm}$; Phenomenex Inc., Torrance, California) column at a 3 $\mathrm{mL} / \mathrm{min}$ flow with a gradient that initiated with $30: 70$ $\mathrm{CH}_{3} \mathrm{CN}-0.1 \%$ formic acid (aqueous) and increased linearly to $100 \% \mathrm{CH}_{3} \mathrm{CN}$ over $30 \mathrm{~min}$.

Metabolite identification.- Pure compounds were identified by nuclear magnetic resonance (NMR) and gas chromatography-mass spectrometry (GC-MS) analyses. NMR experiments were conducted in $\mathrm{CDCl}_{3}$ with a JEOL ECA-500 (JEOL Ltd., Tokyo, Japan); GC-MS profiles were obtained with a Shimadzu apparatus (QP2010) equipped with a

$30.0 \mathrm{~m}$ capillary column (ZB-5MS; Phenomenex). Samples were dissolved in $\mathrm{CHCl}_{3}$ and GCMS solution software was used for data processing. The Shimadzu GC-MS Metabolites Spectral Database and NIST 2008 mass spectral library were used to identify pure compounds.

\section{$\mathrm{R}_{\text {ESULTS }}$}

Molecular study.-The original SSU alignment consisted of 3227 nucleotides. After excluding ambiguous regions, introns and nucleotides from the 59 and 39 ends due to missing data in most sequences, the final SSU dataset consisted of 1059 nucleotides. The original LSU dataset consisted of 2566 nucleotides. After ambiguous regions, introns and 59 and 39 ends were delimited and excluded the final LSU dataset consisted of 1227 nucleotides. Because we did not find significant conflicts between the separate SSU and LSU tree topologies based on PHYML BS (data not shown), we concatenated the two genes. The combined SSU and LSU alignment included 2258 nucleotides. PHYML analyses of the combined genes produced a single most likely tree with a log likelihood value of 220151.62 (F $\mathrm{F}_{\mathrm{IG}}$. 1). All taxa of Minutisphaera grouped in a highly supported clade within the Dothideomycetes with 100\% PHYML BS and $99 \%$ RAxML BS but without significant Bayesian $\mathrm{PP}$ value. In the Minutisphaera clade there were three distinct clades, labeled A, B and C (FIG. 1). Minutisphaera fimbriatispora forms clade A with low support. A strain of Minutisphaera sp. (G155-1a) from North Carolina occurred at the base of this clade, which possessed $78 \%$ RAxML BS, suggesting that it belongs 
TABLE I. Sequences retrieved from GenBank

\begin{tabular}{|c|c|c|c|}
\hline \multirow[b]{2}{*}{ Species } & \multirow[b]{2}{*}{ Voucher information $^{a}$} & \multicolumn{2}{|c|}{ GenBank accession nos. } \\
\hline & & nucSSU rDNA & nucLSU rDNA \\
\hline Aliquandostipite khaoyaiensis & CBS 118232 & - & GU301796 \\
\hline Aulographina pinorum & CBS 174.90 & GU296138 & GU301802 \\
\hline Alternaria alternata & CBS 916.96 & DQ678031 & DQ678082 \\
\hline Alternaria sp. (as Clathrospora diplospora) & CBS 174.51 & DQ678016 & DQ678068 \\
\hline Amniculicola immersa & CBS 123083 & GU456295 & FJ795498 \\
\hline Amniculicola lignicola & CBS 123094 & EF493861 & EF493863 \\
\hline Amniculicola parva & CBS 123092 & GU296134 & FJ795497 \\
\hline Anguillospora longissima & CS869-1D & GU266222 & GU266240 \\
\hline Aquaticheirospora lignicola & RK-2006a & AY736377 & AY736378 \\
\hline Ascorhombispora aquatica & CAI-1H31 & - & EU196548 \\
\hline Asterina phenacis & TH 589 & GU586211 & GU586217 \\
\hline Asterina weinmanniae & TH 592 & GU586212 & GU586218 \\
\hline Asterina zanthoxyli & TH 561 & GU586213 & GU586219 \\
\hline Botryosphaeria dothidea & CBS 115476 & DQ677998 & DQ678051 \\
\hline Botryosphaeria ribis & CBS 115475 & DQ678000 & DQ678053 \\
\hline Capnodium coffeae & CBS 147.52 & DQ247808 & DQ247800 \\
\hline Capnodium salicinum & CBS 131.34 & DQ6779977 & DQ678050 \\
\hline Catinella olivacea & UAMH 10679 & DQ915484 & EF622212 \\
\hline Cheirosporium triseriale & HMAS 180703 & - & EU413954 \\
\hline Cochliobolus heterostrophus & CBS 134.39 & AY544727 & AY544645 \\
\hline Cochliobolus sativus & DAOM 216378 & DQ677995 & DQ678045 \\
\hline Dendryphiella arenaria & CBS 181.85 & DQ471022 & DQ470971 \\
\hline Dothidea insculpta & CBS 189.58 & DQ247810 & DQ247802 \\
\hline Dothidea sambuci & DAOM 231303 & AY544722 & NG_027611 \\
\hline Dothiora cannabinae & CBS 373.71 & DQ479933 & DQ470984 \\
\hline Elisinoë phaseoli & CBS 165.31 & DQ678042 & DQ678095 \\
\hline Elisinoë veneta & CBS 164.29 & DQ678007 & DQ678060 \\
\hline Farlowiella carmichaeliana & CBS 206.36 & AY541482 & AY541482 \\
\hline Gloniopsis praelonga & CBS 112415 & FJ161134 & FJ161173 \\
\hline Gloniopsis smilacis & CBS 114601 & FJ161135 & FJ161174 \\
\hline Guignardia bidwelli & CBS 237.48 & DQ678034 & DQ678085 \\
\hline Hysteropatella clavispora & CBS 247.34 & DQ678006 & AY541493 \\
\hline Hysteropatella elliptica & CBS 935.97 & EF495114 & DQ767657 \\
\hline Jahnula aquatica & R68-1 & EF175633 & EF175655 \\
\hline Jahnula bipileata & AF220-1 & EF175634 & EF175656 \\
\hline Jahnula sangamonensis & A402-1B & EF175639 & EF175661 \\
\hline Laurera megasperma & AFTOL 2094 & GU561841 & FJ267702 \\
\hline Lentithecium aquaticum & CBS 123099 & FJ795477 & FJ795434 \\
\hline Lentithecium arundinaceum & CBS 619.89 & DQ813513 & DQ813509 \\
\hline Lindgomyces cinctosporae & R56-1 & AB522430 & AB522431 \\
\hline Lindgomyces ingoldianus & ATCC $200398^{\mathrm{T}}$ & AB521719 & AB521736 \\
\hline Lindgomyces ingoldianus & JCM16479/NBRC106126 & AB521720 & JF419899 \\
\hline Lindgomyces rotundatus & JCM 16482/NBRC106127 & AB521723 & AB521740 \\
\hline Lophiostoma arundinis & CBS 269.34 & DQ782383 & DQ782384 \\
\hline Lophiostoma crenatum & CBS 629.86 & DQ678017 & DQ678069 \\
\hline Lophiostoma macrostomum & JCM 13545 & AB521731 & AB433273 \\
\hline Lophiostoma macrostomum & JCM 13546/MAFF 239447 & AB521732 & AB433274 \\
\hline Massarina eburnea & HKUCC4054 & AF164366 & - \\
\hline Massarina eburnea & CBS 473.64 & AF164367 & - \\
\hline Megalohypha aqua-dulces & AF005-2a & GU266228 & EF175667 \\
\hline Micropeltis zingiberacicola & IFRDCC 2264 & JQ036222 & JQ036227 \\
\hline Minutisphaera fimbriatispora & A242-7d & HM196373 & HM196366 \\
\hline Minutisphaera fimbriatispora ${ }^{\mathrm{TYPE}}$ & A242-8a & HM196374 & HM196367 \\
\hline
\end{tabular}


TABLE I. Continued

\begin{tabular}{|c|c|c|c|}
\hline \multirow[b]{2}{*}{ Species } & \multirow[b]{2}{*}{ Voucher information ${ }^{a}$} & \multicolumn{2}{|c|}{ GenBank accession nos. } \\
\hline & & nucSSU rDNA & nucLSU rDNA \\
\hline Minutisphaera fimbriatispora & A242-8c & HM196375 & HM196368 \\
\hline Minutisphaera fimbriatispora & G155-1 $\mathrm{a}^{\mathrm{b}}$ & JX474865 & JX474859 \\
\hline Minutisphaera sp. & G156-1a & JX474866 & JX474860 \\
\hline Minutisphaera japonica & JCM 18561/MAFF 243473 & AB733432 & AB733438 \\
\hline Minutisphaera japonica & JCM18562/MAFF 243474 & AB733433 & AB733439 \\
\hline Minutisphaera japonica ${ }^{\text {ТYРЕ }}$ & JCM18560/MAFF 243475 & AB733434 & AB733440 \\
\hline Muyocopron sp. & MFLU (CC) 10-0042 & JQ036225 & - \\
\hline Muyocopron sp. & MFLU (CC) 10-0041 & JQ036226 & JQ036230 \\
\hline Mytilinidon andinense & CBS 123562 & FJ161159 & FJ161199 \\
\hline Mytilinidon mytilinellum & CBS 303.34 & FJ161144 & FJ61184 \\
\hline Mycosphaerella fijiensis & OSC 100622 & DQ767652 & DQ678098 \\
\hline Mycosphaerella graminicola & CBS 292.38 & DQ678033 & DQ678084 \\
\hline Myriangium duriaei & CBS 260.36 & AY016347 & DQ678059 \\
\hline Natipusilla decorospora-1a & AF236-1a & HM196376 & HM196369 \\
\hline Natipusilla limonensis-1a & AF286-1a & HM196377 & HM196370 \\
\hline Natipusilla limonensis & PE3-2a & JX474867 & JX474861 \\
\hline Natipusilla limonensis & PE3-2b & JX474870 & JX474862 \\
\hline Natipusilla naponensis & AF217-1a & HM196378 & HM196371 \\
\hline Natipusilla naponensis & AF217-1b & HM196379 & HM196372 \\
\hline Natipusilla bellaspora & PE91-1a & JX474868 & JX474863 \\
\hline Natipusilla bellaspora & PE91-1b & JX474869 & JX474864 \\
\hline Neomicrothyrium siamense & IFRDCC 2194 & JQ036223 & JQ036228 \\
\hline Paramicrithyrium chinensis & IFRDCC 2258 & JQ036224 & JQ036229 \\
\hline Patellaria atrata & CBS 958.97 & GU296181 & GU301855 \\
\hline Roccellographa cretacea & DUKE 191Bc & DQ883705 & DQ883696 \\
\hline Schismatomma decolorans & DUKE 0047570 & $\begin{array}{l}\text { AY548809 } \\
\text { nucSSU rDNA }\end{array}$ & $\begin{array}{l}\text { AY548815 } \\
\text { nucLSU rDNA }\end{array}$ \\
\hline Stomiopeltis betulae & CBS 114420 & GU214701 & GU214701 \\
\hline Tingoldiago graminicola & JCM 16485/NBRC $106131^{\mathrm{T}}$ & AB521726 & AB521743 \\
\hline Tingoldiago graminicola & JCM 16486/NBRC 106132 & AB521728 & AB521745 \\
\hline Trypethelium nitidiusculum & AFTOL 2099 & GU561842 & FJ267701 \\
\hline
\end{tabular}

${ }^{\text {a }}$ Source abbreviations: ${ }^{\text {TYPE }}$ Type Strains; CBS, Centraalbureau voor Schimmelcultures, Utrecht, the Netherlands; CS, and A, Carol Shearer, University of Illinois, Plant Biology Culture Collection; CAI, Lei Cai; RK, Rumpai Kodsueb; TH, T.A. Hoffmann; DAOM, Canadian Collection of Fungi Cultures in Ottawa, Ontario; UMAH, University of Alberta Microfungus Collection and Herbarium; R, Raja H., University of Illinois, Plant Biology Culture Collection; AF, Astrid Ferrer, University of Illinois, Plant Biology Culture Collection; AFTOL, Assembling the Fungal Tree of Life; ATCC, American Type Culture Collection; G, University of North Carolina, Greensboro, Department of Chemistry and Biochemistry Fungal Culture Collection; JCM, Japan Collection of Microorganisms; MAFF, the Ministry of Agriculture, Forestry and Fisheries, Japan; NBRC, National Biological Resources Center, Japan; HKUCC, University of Hong Kong Culture Collection; IFRDCC, International Fungal Research and Development Culture Collection; MFLU(CC), Mae Fah Luang University Culture Collection; OSC, Oregon State University Herbarium, Corvallis, Oregon Genome Databases; PE; Peru freshwater ascomycetes, Department of Plant Biology Culture Collection; DUKE, Duke University Herbarium, Durham, North Carolina.

${ }^{\mathrm{b}}$ Newly generated sequences are in boldface.

to M. fimbriatispora. Isolates of the newly collected species from Japan formed a well supported clade (B) with $85 \%$ PhyML BS, 93\% RAxML BS and significant PP; this clade was sister to the M. fimbriatispora isolates. Clade C consists of Minutisphaera sp. (G156-1a) that occurred on an independent branch sister to $M$. fimbriatispora isolates (A242 and G155) but without significant Bayesian PP and/or PHYML and RAxML BS ( $\mathrm{F}_{\mathrm{IG}}$. 1). Our molecular results also suggest that $M$. japonica is not phylogenetically related to Natipusilla spp. and adds further support to the establishment of Natipusillaceae by Raja et al. (2012) in that all the species currently described in this family formed a monophyletic clade with 100\% PHYML and RAxML BS as well as significant BS PP (FIG. 1$)$.

The ITS dataset included 10 strains of Minutisphaera spp. and consisted of 687 nucleotides including the primer regions at the 59 and 39 ends. 
TABLE II. Newly generated ITS sequences from strains of Minutisphaera spp.

\begin{tabular}{|c|c|c|c|}
\hline Species & Voucher information & Substrate and locality & $\begin{array}{c}\text { GenBank } \\
\text { accession nos. } \\
\text { nucITS rDNA }\end{array}$ \\
\hline Minutisphaera fimbriatispora & A $242-7 c^{a}$ & Submerged wood, IL, USA & JX474871 \\
\hline Minutisphaera fimbriatispora & A $242-7 d^{a}$ & Submerged wood, IL, USA & JX474872 \\
\hline Minutisphaera fimbriatispora & G155-1a & Submerged wood, NC, USA & JX474873 \\
\hline Minutisphaerafimbriatispora & G155-1b & Submerged wood NC, USA & JX474874 \\
\hline Minutisphaera japonica & JCM 18561/MAFF 243473 & Submerged wood, Japan & AB733435 \\
\hline Minutisphaera japonica & JCM 18562/MAFF 243474 & Submerged wood, Japan & AB733436 \\
\hline Minutisphaera japonica TYРЕ & JCM 18560/MAFF 243475 & Submerged wood, Japan & AB733437 \\
\hline Minutisphaera sp. & G156-1a & Submerged wood, NC, USA & JX474875 \\
\hline Minutisphaera sp. & G156-2a & Submerged Pinus wood, NC, USA & JX474876 \\
\hline Minutisphaera sp. & G156-2b & Submerged Pinus wood, NC, USA & JX474877 \\
\hline
\end{tabular}

${ }^{a}$ Specimens examined by Ferrer et al. 2011.

After the ends were trimmed and ambiguous regions excluded using Gblocks, the final ITS alignment contained 605 nucleotides. PHYML analyses of the ITS dataset generated a single most likely tree with a $\log$ likelihood value of 21334.69 (FIG. 2). Minutisphaera japonica (clade B) formed a distinct monophyletic group with 100\% PHYML BS, 100\% RAxML $\mathrm{BS}$, and $\$ 95 \% \mathrm{PP}$, indicating that it is distinct from the M. fimbriatispora clade (A242 7c, 7d and G155-1a, b), which possessed $97 \%$ PHYML BS and $99 \%$ RAxML BS. Two other strains of Minutisphaera in clades C (G156-1) and D (G156-2) may be new taxa in that they are placed in separate groups from both $M$. fimbriatispora and M. japonica and each other. However, we have retained them as Minutisphaera spp. until additional specimens become available for further investigation.

We calculated the uncorrected p-distances with PAUP* 4.0b10 (Swofford 2002). P-distance calculates the proportion of nucleotide sites that differ between any two sequences. The p-distance can be obtained by dividing the number of nucleotide differences by the total number of nucleotides being compared. In this study as well as a previous study on freshwater Dothideomycetes (Raja et al. 2011b), we used the following criterion to delimit species based on ITS data. To be considered the same species based on ITS data, the taxa being compared should have \$ 97\% similarity. Among ITS sequences, the average intraspecific variation among different species of Minutisphaera was $1.8 \%$ whereas the average interspecific difference was $6.7 \%$ (data not shown).

The molecular phylogenetic analyses of both the combined SSU and LSU (FIG. 1), as well as the ITS phylogeny ( $\left.\mathrm{F}_{\mathrm{IG}} .2\right)$, clearly support the establishment of $M$. japonica as a new and separate taxon within Minutisphaera. This placement also is corroborated by morphological data. The taxon from Japan therefore is described and illustrated herein as a new species.

\section{$\mathrm{T}_{\text {AXONOMY }}$}

When Ferrer et al. (2011) established the genus Minutisphaera, they described the ascomata of the type species, $M$. fimbriatispora, as superficial to partly immersed, brown, globose to subglobose, ostiolate, with irregular dark brown hyphae-like structures on the upper part of the ascomata. We observed that ascomata formed on the natural substrate and those formed in axenic culture (M. japonica) appear more apothecial at maturity (FIGs. 3-6, 22, 30, 31) than those of the original collections. The ascospores of the fungus from Japan do not possess filamentous appendages around the mid-septum. To include these newly found, additional morphological characters, we emend the genus description of Minutisphaera to reflect these observations. The key morphological features distinguishing the Minutisphaera species are summarized ( $\left.\mathrm{T}_{\mathrm{ABLE}} \mathrm{III}\right)$.

Minutisphaera Shearer, A.N. Mill. \& Ferrer, emend Ascomata on submerged wood, small, globose to subglobose, or apothecioid, erumpent to superficial, brown, with an ostiole and irregularly curved, dark brown to black hyphae-like structures around the ostiole. Peridium thin-walled, composed of textura angularis to globosum. Pseudoparaphyses septate, with or without enlarged pigmented tips. Asci fissitunicate, eight-spored, ovoid to obclavate, lacking a stalk, rounded at apex. Ascospores 1-2-septate, clavate, multiguttulate, hyaline becoming pale brown, with fusiform gelatinous sheath, with or without numerous filamentous appendages radiating around the midseptum. 


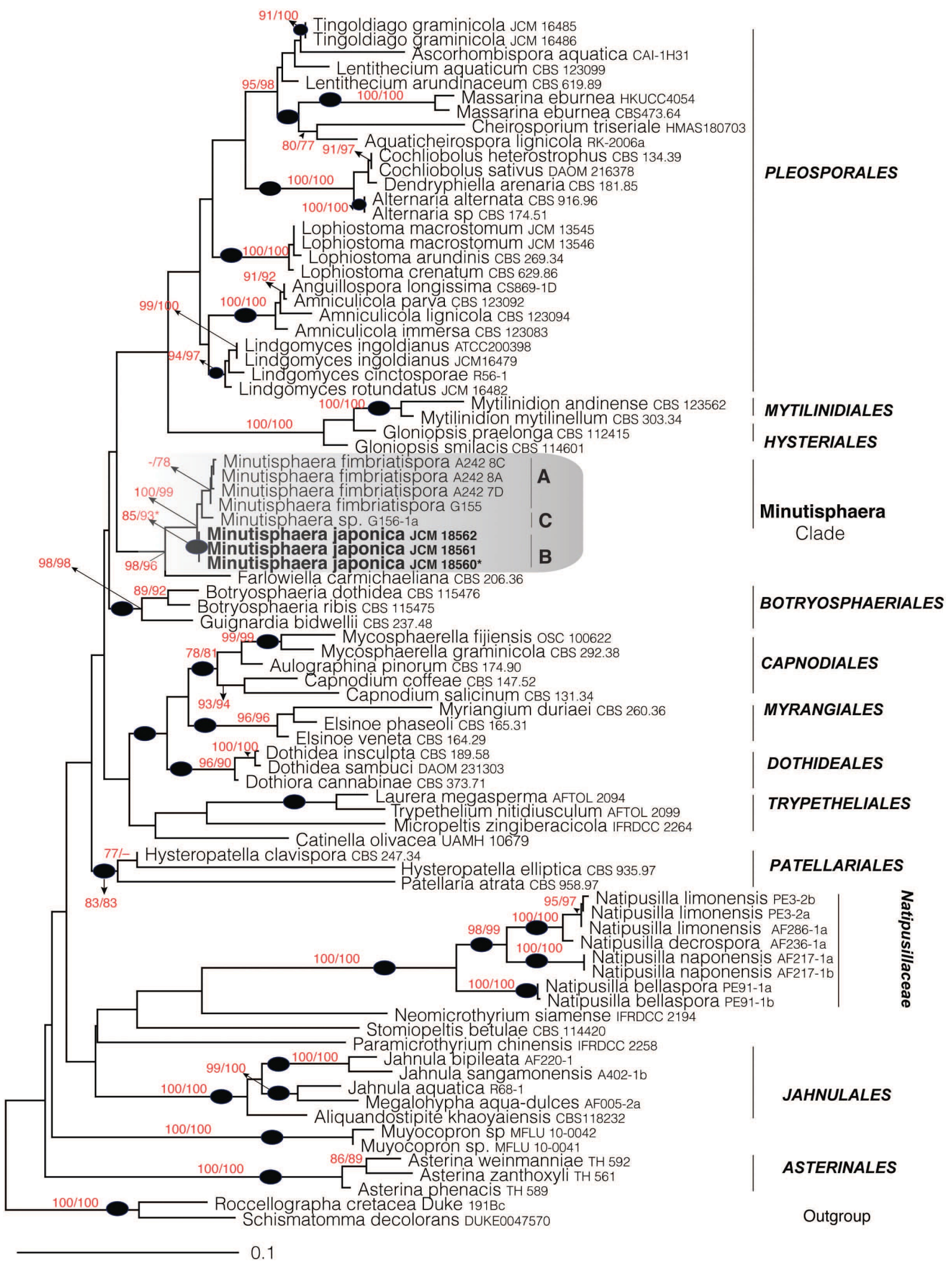

FIG. 1. Phylogram of the most likely tree (2lnL 5 20151.62) from a PHYML analysis of 83 taxa based on combined SSU and LSU nrDNA (2258 bp). Branches with a black oval indicate Bayesian posterior probabilities $\$ 95 \%$; numbers refer to PhyML/RAxML bootstrap support values $\$ 70 \%$ based on 1000 replicates. An asterisk indicates type specimen. Bar indicates nucleotide substitution per site. Members of Arthoniomycetes were used as outgroup taxa. 


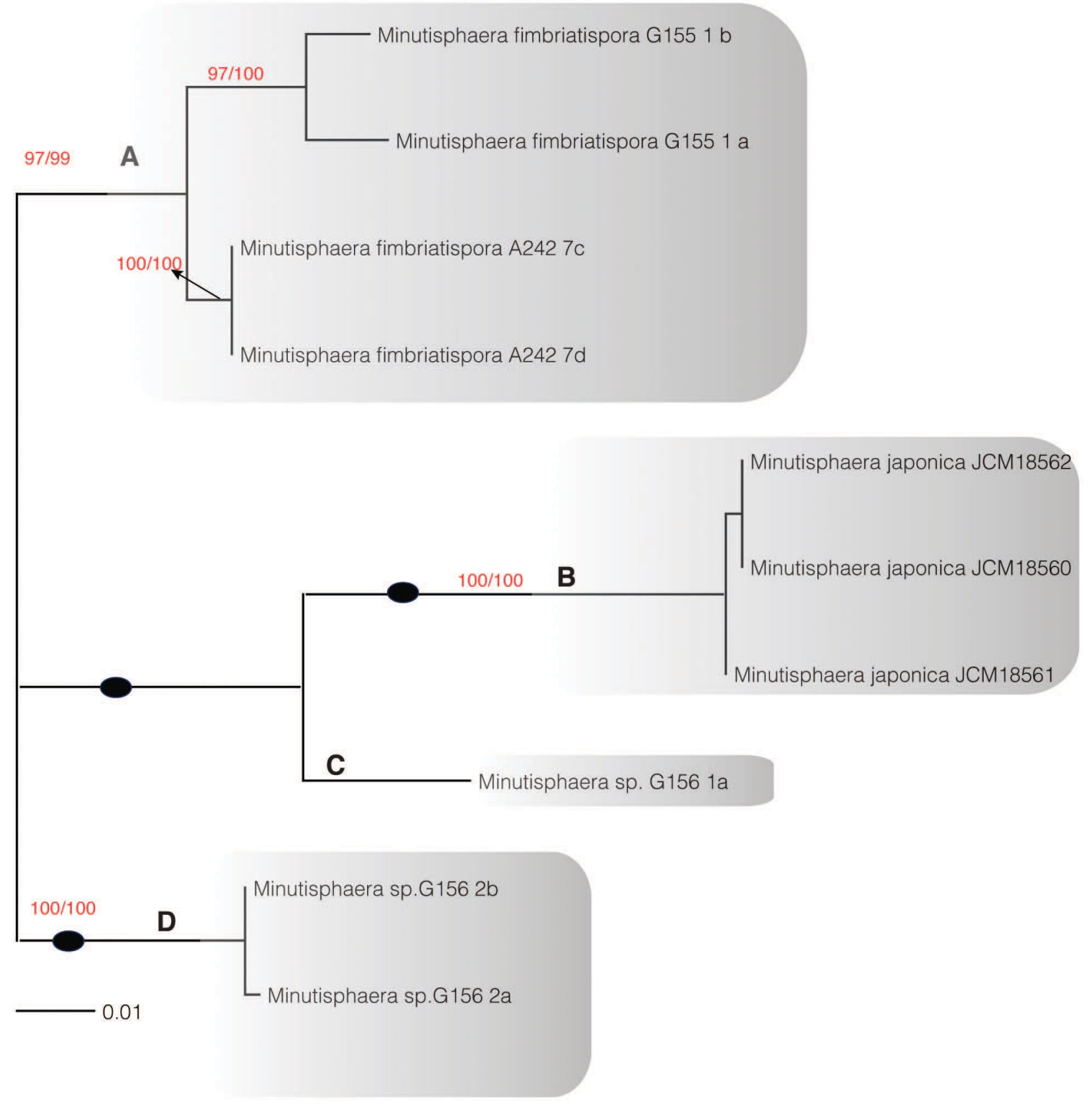

FIG. 2. Phylogram of the most likely tree (2lnL 5 1334.69) from a PHYML analysis of 10 strains of Minutisphaera based on ITS nrDNA (605 bp). Support values as in FIG. 1.

Type species: M. fimbriatispora Shearer, A.N. Mill. \& Ferrer, Ferrer et al., Mycologia103:415, 2011.

The foregoing description is based on that provided by Ferrer et al. (2011) with these emendments: ascomata sometimes apothecioid; pseudoparaphyses with enlarged tips; ascospores hyaline becoming pale brown, 1-3-septate, with or without gelatinous sheath and appendages radiating around the mid-septum.
Minutisphaera japonica Kaz. Tanaka, Raja, \& Shearer sp. nov.

FIGs. 3-21.

MycoBank MB801286

Ascomata on wood 90-130 mm high, 150-300 mm diam, superficial, scattered or in clusters of 2-3, apothecioid at maturity but not hysterithecioid, globose with a flattened top and base, dark brown to dull black, with slightly incurved margin (FIGs. 36). Beak absent. Ascomal wall in longitudinal section 
TABLE III. Comparison of selected morphological characters among Minutisphaera spp.

\begin{tabular}{|c|c|c|c|c|}
\hline & $\begin{array}{l}\text { Minutisphaera } \\
\text { fimbriatispora }\end{array}$ & $\begin{array}{l}\text { Minutisphaera } \\
\text { japonica }\end{array}$ & $\begin{array}{l}\text { Minutisphaera } \\
\text { sp. G156-1 }\end{array}$ & $\begin{array}{l}\text { Minutisphaera } \\
\text { sp. G156-2 }\end{array}$ \\
\hline Habitat & Freshwater & Freshwater & Freshwater & Freshwater \\
\hline Substrate & Woody debris & Woody debris & Woody debris & Woody debris of Pinus sp. \\
\hline Ascomata & $\begin{array}{l}\text { Black, minute; globose } \\
\text { to subglobose, } \\
\text { ostiolate; perithecoid } \\
\text { or apothecioid, } \\
\text { collabent }\end{array}$ & $\begin{array}{l}\text { Brown to black, minute; } \\
\text { apothecioid at maturity, } \\
\text { with flattened base }\end{array}$ & $\begin{array}{l}\text { Black, minute; } \\
\text { apothecioid at } \\
\text { maturity }\end{array}$ & $\begin{array}{l}\text { Black, minute; } \\
\text { apothecioid at } \\
\text { maturity }\end{array}$ \\
\hline Peridium & $\begin{array}{l}\text { Membranous, } \\
\text { 2-cell layers wide; } \\
\text { with dark } \\
\text { hyphae-like } \\
\text { apical structures }\end{array}$ & $\begin{array}{l}\text { Membranous, composed } \\
\text { of } 2 \text { zones, inner zone of } \\
\text { rectangular to sub-globose } \\
\text { hyaline cells; outer zone } \\
\text { with dark hyphae-like } \\
\text { apical structures }\end{array}$ & $\begin{array}{l}\text { Membranous; with } \\
\text { dark hyphae-like } \\
\text { apical structures }\end{array}$ & $\begin{array}{l}\text { Membranous; with dark } \\
\text { hyphae-like apical } \\
\text { structures }\end{array}$ \\
\hline Asci & $\begin{array}{l}\text { Numerous, oblong } \\
\text { to obclavate, } \\
\text { broadly rounded, } \\
\text { 8-spored } \\
\text { 52-97 } 3 \text { 18-31 mm } \\
\text { (A242-8, Type } \\
\text { specimen) } \\
\text { 58-88 } 318-22 \mathrm{~mm} \\
\text { (G155) }\end{array}$ & $\begin{array}{l}\text { Obovoid to broadly } \\
\text { cylindrical, broadly } \\
\text { rounded, 8-spored } \\
55-82.5321 .5-32.5 \mathrm{~mm}\end{array}$ & $\begin{array}{l}\text { 8-spored } \\
48-51317-19 \mathrm{~mm}\end{array}$ & $\begin{array}{l}\text { Numerous, broadly } \\
\text { clavate, rounded and } \\
\text { thickened at the apex, } \\
\text { 8-spored } \\
57-70315-23 \mathrm{~mm}\end{array}$ \\
\hline Ascospores & $\begin{array}{l}\text { One-septate, hyaline } \\
\text { when young } \\
\text { becoming golden } \\
\text { brown with age; } \\
\text { clavate, with a } \\
\text { supramedian } \\
\text { septum; upper } \\
\text { cell broader, and } \\
\text { shorter than tapering } \\
\text { basal cell; with } \\
\text { gelatinous sheath } \\
\text { and numerous } \\
\text { filamentous } \\
\text { appendages } \\
24-3636-8 \text { mm } \\
\text { (A242-8, Type } \\
\text { specimen) 22- } \\
283 \text { 6-7 mm } \\
\text { (G155) }\end{array}$ & $\begin{array}{l}\text { One-septate, hyaline when } \\
\text { young becoming brown } \\
\text { with age; broadly fusiform, } \\
\text { slightly curved; with a } \\
\text { submedian primary } \\
\text { septum, upper } \\
\text { hemisphere broader } \\
\text { than lower hemisphere, } \\
\text { slightly constricted at the } \\
\text { mid-septum, acute at the } \\
\text { apex, rounded at the } \\
\text { base; surrounded by an } \\
\text { amorphous gelatinous } \\
\text { sheath (1-3 mm thick) } \\
\text { 25-33 } 39-11 \mathrm{~mm}\end{array}$ & $\begin{array}{l}\text { One-septate; with a } \\
\text { supramedian septum; } \\
\text { upper cell broader, } \\
\text { and shorter than } \\
\text { tapering basal cell; } \\
\text { with gelatinous sheath } \\
\text { and numerous } \\
\text { filamentous } \\
\text { appendages radiating } \\
\text { from the mid-septum } \\
\text { 20-23 } 35-6 \text { mm }\end{array}$ & $\begin{array}{l}\text { One-septate, hyalinewhen } \\
\text { young becoming, three- } \\
\text { septate and golden } \\
\text { brown with age; clavate, } \\
\text { with a supramedian } \\
\text { septum; upper cell } \\
\text { broader, and shorter } \\
\text { than tapering basal cell; } \\
\text { with gelatinous sheath } \\
\text { and numerous } \\
\text { filamentous } \\
\text { appendages radiating } \\
\text { from the mid-septum } \\
\text { 18-25 } 35-8 \text { mm }\end{array}$ \\
\hline References & $\begin{array}{l}\text { Ferrer et al. 2011, This } \\
\text { study }\end{array}$ & This study & This study & This study \\
\hline
\end{tabular}

laterally 15-25 mm wide, of two zones; outer zone $7-$ $15 \mathrm{~mm}$ wide of 1-3 layers of polygonal to subglobose brown cells 5-20 3 5-15 mm, with short, thick-walled, dark brown irregularly shaped hairs 7-12 $32.5-3.5 \mathrm{~mm}$ around upper outer wall; inner zone 6-12.5 mm wide, of 2-3 layers of rectangular to subglobose hyaline cells 2-4 3 1.5-2 mm (FIgs. 6-8). Pseudoparaphyses 1.5$3 \mathrm{~mm}$ wide, $70-110 \mathrm{~mm}$ long, septate, branched; tips of pseudoparaphyses enlarged $3.5-4.5 \mathrm{~mm}$ thick and pigmented as in a pseudoepithecium (FIGs. 9, 10).
Asci 55-82.5 3 21.5-32.5 mm (av. $566.8326 .5 \mathrm{~mm}, \mathrm{n}$ 5 60), obovoid to broadly cylindrical, fissitunicate, basal, rounded at the

apex, with shallow apical chamber, sessile to shortstalked, with eight biseriate to triseriate ascospores (FIGs. 11-15). Ascospores 25-33 39-11 mm (average 529.039 .7 mm, n 5 60), L/W 2.5-3.4 (av. 5 3.0, n 5 $60)$, broadly fusiform, slightly curved, with a median to submedian primary septum (0.50-0.58; av. 50.54 , n 5 $60)$, upper hemisphere broader than lower hemi- 

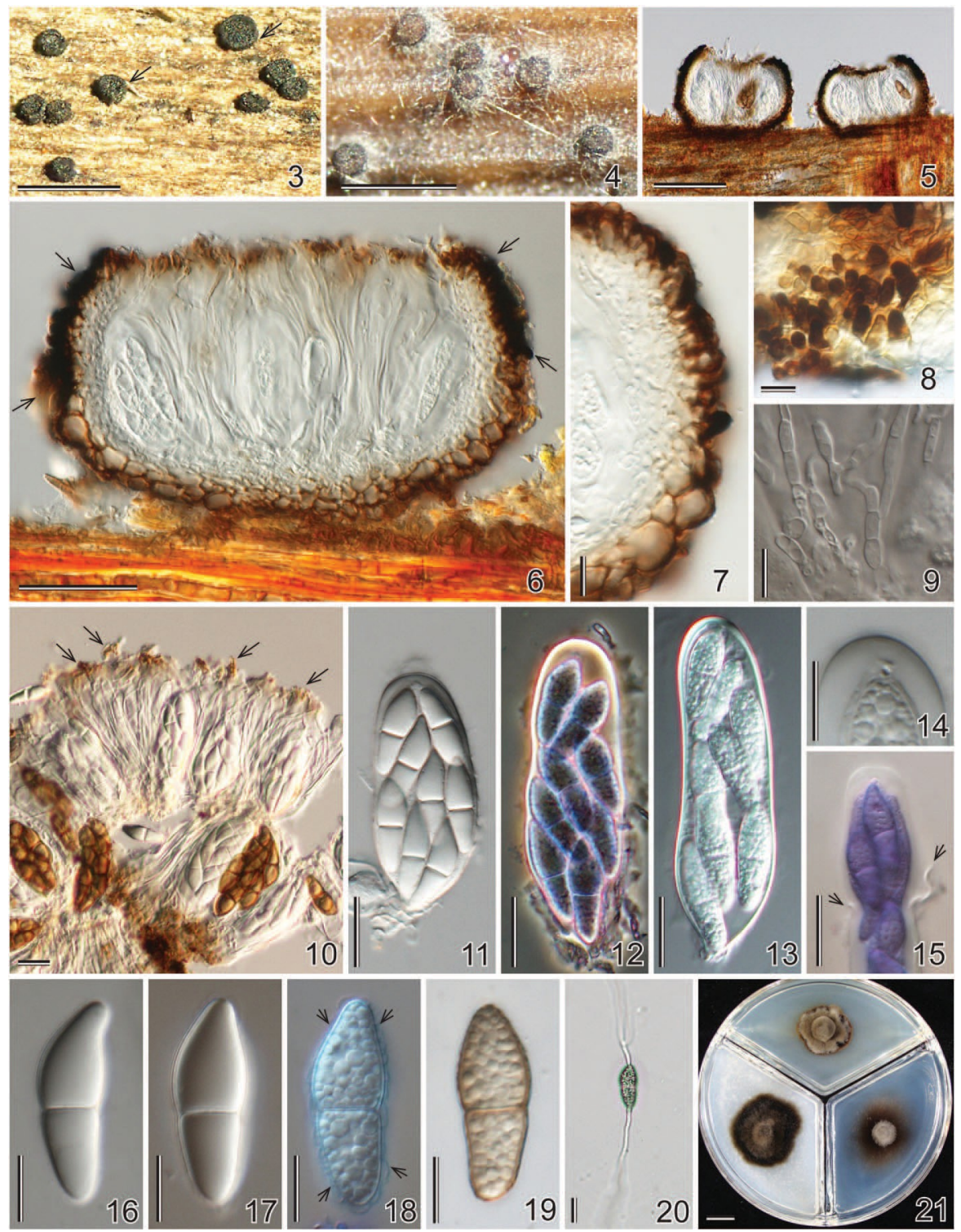

FIgs. 3-21. Minutisphaera japonica. 3. Apothecioid ascomata of HHUF 30098 on natural substratum (arrows), bar 5 $500 \mathrm{~mm}$. 4. Ascomata of JCM 18562 in culture, bar $5500 \mathrm{~mm}$. 5, 6. Ascomata in longitudinal section from HHUF 30098, arrows indicate dark hyphae-like structures on ascomatal wall, bars $5100 \mathrm{~mm}$. 7. Ascomatal wall of HHUF 30098, bar 510 mm. 8. Dark hyphae-like structures on ascomata surface from HHUF 30098, bar $510 \mathrm{~mm}$. 9. Pseudoparaphyses from JCM 18562 , bar 5 $10 \mathrm{~mm}$. 10. Pseudoparaphyses with enlarged tips (arrows) and asci from HHUF 30096, bar $520 \mathrm{~mm}$. 11-13. Asci from HHUF 30098 (11), JCM 18562 (12) and JCM 18560, (13) bar $520 \mathrm{~mm}$. 14. Apex of ascus from JCM 18560 with a shallow apical chamber, bar $510 \mathrm{~mm}$. 15. Fissitunicate ascus from JCM 18562. Arrows indicate ectoascus, bar 5 20 mm. 16-19. Ascospores from HHUF 30096 (16) and HHUF 30098 (17, 19), bars $510 \mathrm{~mm}$. 18. Arrows indicate gelatinous sheath of ascospore staining with black-blue ink, from JCM 18562, bar $510 \mathrm{~mm}$. 20. Germinating ascospore of HHUF 30096, bar 5 20 mm. 21. Colonies of JCM 18560 on PDA (upper), wOA (left), and CMA (right) after $25 \mathrm{~d}$ at $25 \mathrm{C}$ in the dark, bar $51 \mathrm{~cm}$.

sphere, slightly constricted at the mid-septum, acute at the apex, rounded at the base, hyaline but becoming brown with age, smooth, with small guttules when fresh, surrounded by an amorphous gelatinous sheath (1-3 mm thick) staining with blue-black ink (FIGs. 1619). Germinating from both ends of ascospores (FIG. 20).
Cultural characters: Colonies on PDA attaining 21$22 \mathrm{~mm}$ diam within $25 \mathrm{~d}$ at $25 \mathrm{C}$ in the dark, surface velvety in appearance, grayish sepia to smoke gray (Rayner 1970), with an irregular margin. On wOA attaining $25-27 \mathrm{~mm}$ diam in the same conditions, fuscous black to dark mouse gray. On CMA attaining 36-39 $\mathrm{mm}$ diam in the same conditions, gray 

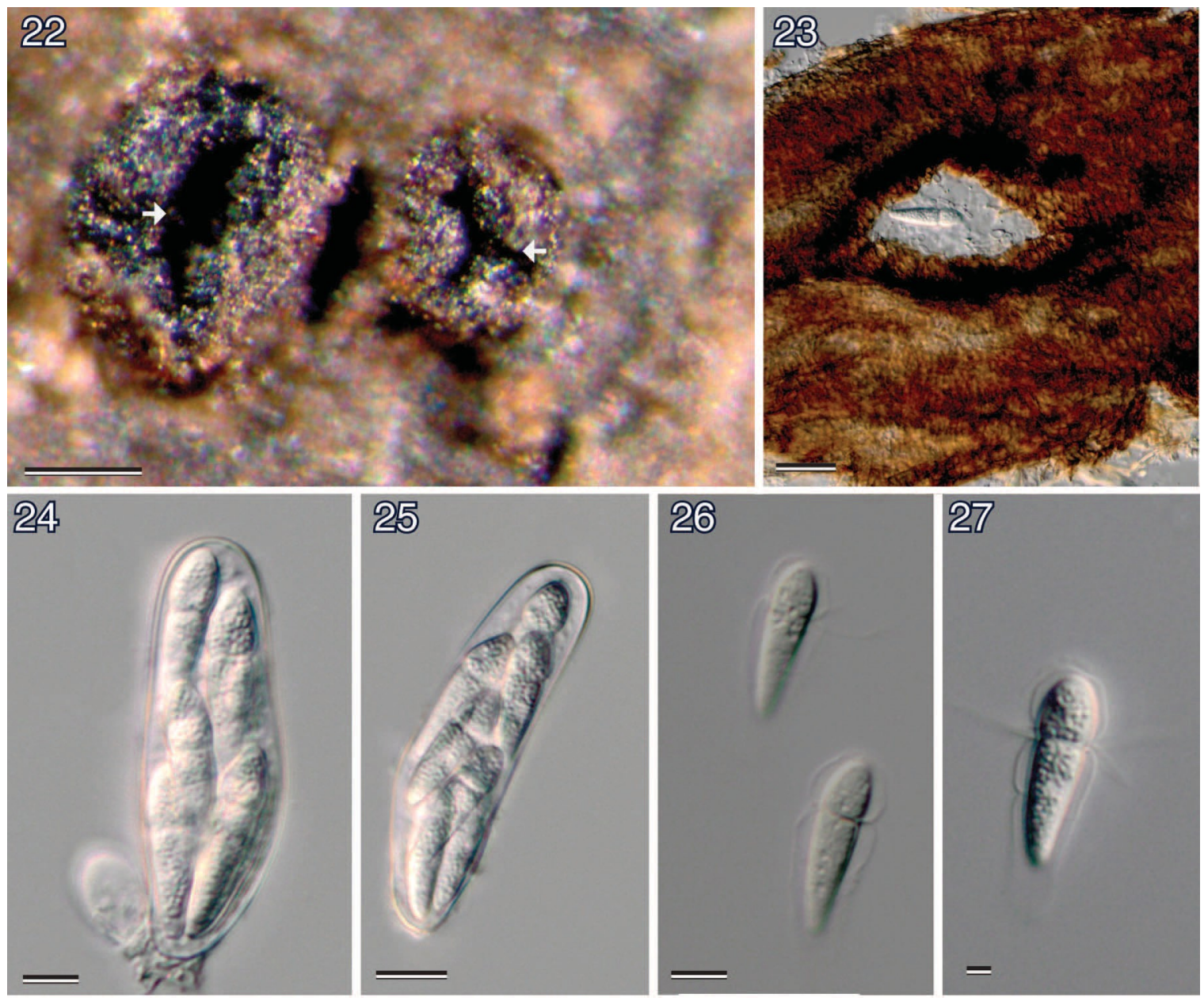

FIGs.22-27. Minutisphaera fimbriatispora (G155-1).22. Apothecioid ascomata on surface, note how the ostiole opens up to expose the hymenial layer, giving it an apothecioid appearance (arrows), bar $5100 \mathrm{~mm}$. 23. Squash mount of the ascomata showing dark hyphae-like structures around the ostiole, bar $550 \mathrm{~mm}$. 24. Clavate ascus, bar $510 \mathrm{~mm}$. 25. Clavate ascus, bar 5 $20 \mathrm{~mm} .26,27$. Ascospores showing gelatinous sheath and filamentous appendages. 26, bar $510 \mathrm{~mm} 27$. bar $55 \mathrm{~mm}$.

olivaceous to Hazel (see FIG. 21). On RSA, apothecial ascomata are produced on the surface of rice straw within 2 mo. Asci produced in culture are relatively longer than those formed on natural substratum, but ascospores are almost identical to those found in natural collections: asci (65-)80-105(-128) 3 (20-) 22-27.5(-29) $\mathrm{mm}$ (av. $93.5324 .9 \mathrm{~mm}$, n 5 53); ascospores (24-)28-36(-38) 39.5-13 mm (av. 31.93 $11.3 \mathrm{~mm}$, n 5 100), L/W 2.4-3.3 (av. 2.8, n 5 100), with a submedian primary septum (0.51-0.57 [-0.60]; av. 0.54, n 5 100). Forcible discharge of ascospores from ascus apex observed.

Anamorph: None observed.

Habitat: On submerged wood in rivers.

Known distribution: Japan.

Etymology: "japonica" referring to the country where the new species was collected.

Specimens examined: JAPAN, Aomori, Hirakawa, Aseishiriver, $40.517222 \mathrm{~N}, 140.7675 \mathrm{E}$, on submerged wood, 2 Aug
2003, K. Tanaka \& N. Asama, KT 1352 (HHUF 30095; single ascospore isolate JCM 185615 MAFF 243473); Aomori, Nishimeya, Seisyu-trail, Ooshirosawa-stream, 40.547777N, 140.441944E, on submerged wood, 28 Aug 2010, K. Tanaka, K. Hirayama \& K. Honda, KT 2736 (HHUF 30096; single ascospore isolate JCM 185625 MAFF 243474); ibid, KT 2737 (HHUF 30097); ibid, KT 2738 (HHUF 30098, HOLOTYPUS designated here; single ascospore isolate JCM 185605 MAFF 243475).

Comments: The distinctive features of $M$. japonica occur mainly in the ascospores, which are relatively wider (9-11 $\mathrm{mm}$ in $M$. japonica vs. up to $8 \mathrm{~mm}$ in $M$. fimbriatispora), constricted at the submedian primary septum (vs. supramedian), and without filamentous appendages $\left(\mathrm{T}_{\mathrm{ABLE}} \mathrm{III}\right)$.

Minutisphaera fimbriatispora Shearer, A.N. Mill. \& Ferrer, Mycologia 103:415, $2011 \quad$ FIGs. 22-27 Anamorph: None observed. 

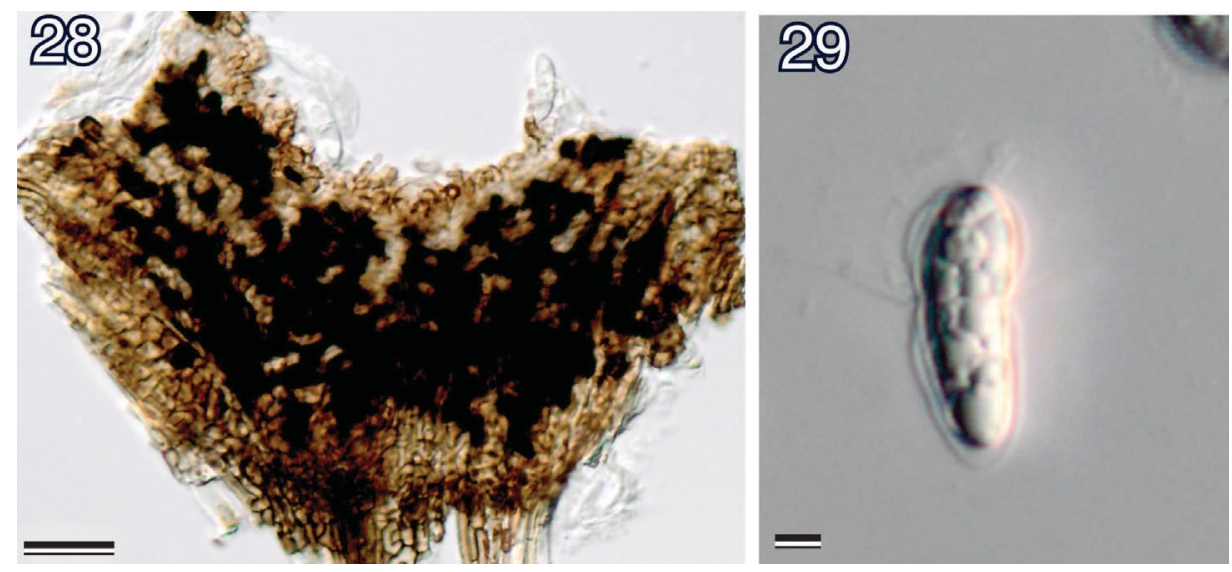

Figs. 28-29. Minutisphaera sp. (G156-1). 28. Squash mount of the ascomata showing dark hyphae-like structures, bar 5 $20 \mathrm{~mm}$. 29. Ascospores mounted in water with gelatinous sheath and appendages, bar $55 \mathrm{~mm}$.

Habitat: On submerged, dead, corticated or partially decorticated woody debris.

Known distribution: USA: Illinois, North Carolina, Virginia.

Cultural characters: Colonies on PDA attaining $21 \mathrm{~mm}$ diam within $25 \mathrm{~d}$ at $25 \mathrm{C}$ in light and dark, surface cotton-like in appearance with some guttation droplets, light gray.

Specimen examined: USA. North Carolina: Piedmont Plateau, Bur-Mil Park, Greensboro, Lake Brandt, 36.170556 $\mathrm{N}, 79.868333 \mathrm{~W}$, on submerged decorticated wood, 20 Oct 2011, H. Raja, G155-1.

Comments: The specimen from North Carolina agrees well with the type description of $M$. fimbriatispora provided by Ferrer et al. (2011). The ascomata of the North Carolina collection (G155-1) were more apothecioid ( $\mathrm{F}_{\mathrm{IG}}$. 22) than those of the type collection. When the ascomata are young they appear more globose to subglobose, however, at maturity the ostiole tends to widen, and the upper surface of the ascomata becomes more collabent. The aging process subsequently exposes the centrum, giving it an apothecioid appearance.

Results of both molecular phylogenetic analyses (FIGS. 1,2) as well as morphological examination (FIGs. 22-27) suggest that G155-1a and M. fimbriatispora are conspecific.

Chemistry: From the organic extract of M. fimbriatispora (G155-1a), two major compounds were isolated and identified as palmitic acid and $(E)$-hexadec-9-en1-ol (Supplementary figs. 1,2 ) by comparison of their NMR data with those reported previously (Dictionary of Natural Products, www.chemnetbase. com) and by using the GC-MS Metabolites Spectral Database and NIST 2008 mass spectral library (Babushok et al. 2007).
Minutisphaera sp. G156-1

FIGs. 28, 29

Anamorph: None observed.

Cultural characters: Colonies on PDA attaining $20 \mathrm{~mm}$ diam within $25 \mathrm{~d}$ at $25 \mathrm{C}$ in light and dark; surface uneven and velvety, light brown to smoke gray with an irregular margin.

Habitat: On submerged wood in a swamp.

Known distribution: USA. North Carolina.

Specimen examined: USA. North Carolina: Piedmont Plateau, Bur-Mil Park, Greensboro, swampy area behind Lake Brandt, $36.167778 \mathrm{~N}, 79.868333 \mathrm{~W}$, on submerged decorticated wood, 20 Oct 2011, H. Raja, G156-1.

Comments: The ascomata of G156-1 resemble those of M. fimbriatispora in havingirregulardark brownhyphaelike structures on the upper part of the ascoma wall (FIG. 28). A gelatinous sheath and filamentous medial appendages extend from the ascospores ( $\mathrm{F}_{\mathrm{IG}}$. 29). Dimensions of the ascospores (20-23 3 5-6 mm) and asci (48-51 $317-19 \mathrm{~mm}$ ) were smaller than those of $M$. fimbriatispora (Ferrer et al. 2011) ( $\left.\mathrm{T}_{\mathrm{ABLE}} \mathrm{III}\right)$.

Molecular analyses of combined SSU and LSU

(FIG. 1) as well as the ITS phylogeny (FIG. 2) separates G156-1a (clade C) from M. fimbriatispora (clade A) as well as M. japonica (clade B). At present we retain this fungus as Minutisphaera sp. because we do not have adequate material for detailed investigation. Further collections as well as molecular phylogenetic analysis of additional axenic culture isolates using ITS and/or perhaps a single-copy protein coding gene such as $M C M 7$, which can provide good resolution for species-level relationships among Dothideomycete taxa (Raja et al. 2011a), might shed light on the phylogenetic relationships of this fungus.

Chemistry: From the organic extract of Minutisphaera sp. (G156-1), two major compounds were isolated and identified as palmitic acid and 

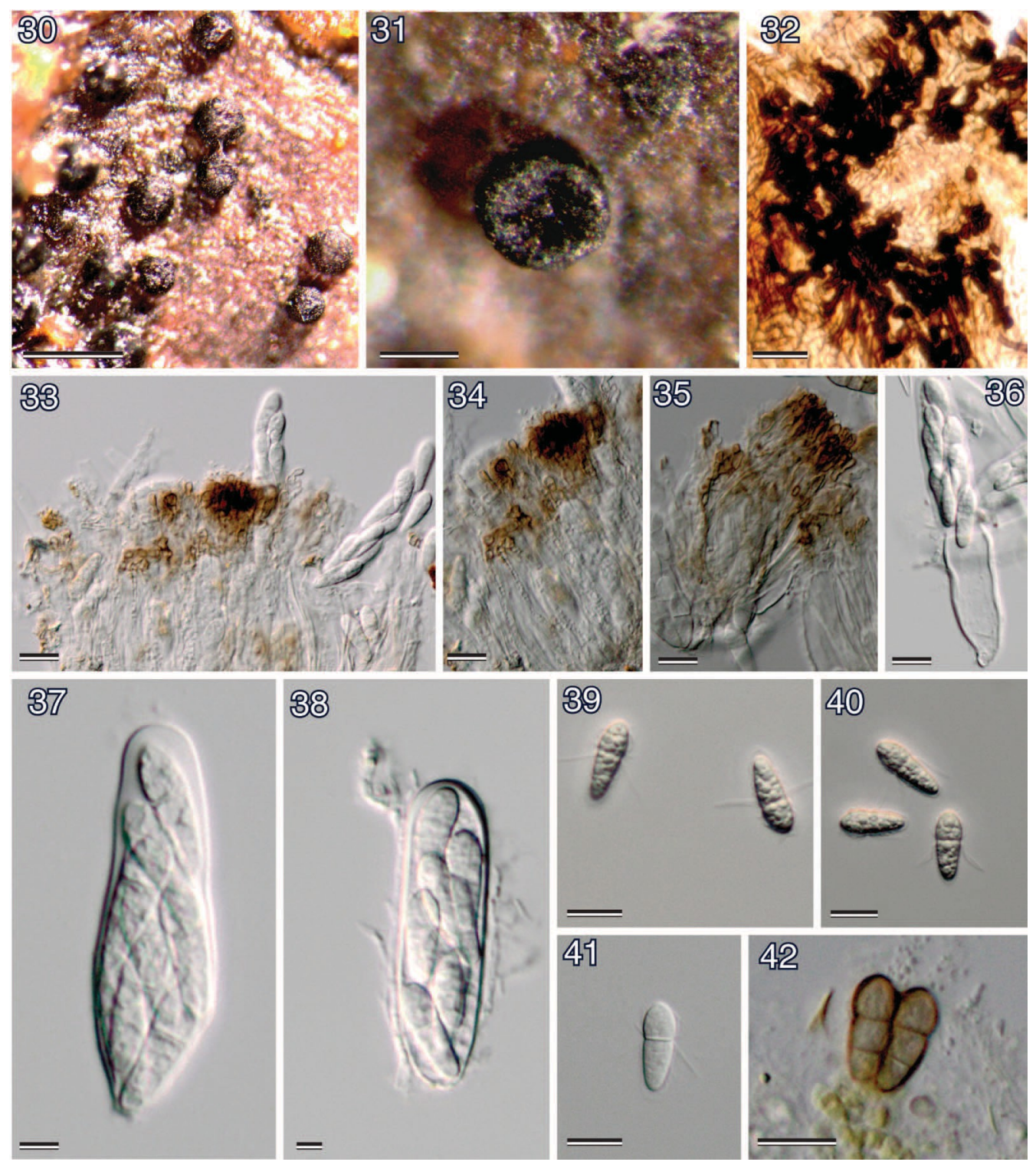

FIGS. 30-42. Minutisphaera sp. (G156-2). 30. Ascomata on natural substratum, bar $5200 \mathrm{~mm}$. 31. Single ascoma with collabent surface, bar $5100 \mathrm{~mm}$. 32. Dark hyphae-like structure on ascomata surface, bar $550 \mathrm{~mm}$. 33 . Asci with pseudoparaphyes, bar $510 \mathrm{~mm}$. 34, 35. Note pseudoparaphyses showing enlarged tips that become brown with age, bars 5 $10 \mathrm{~mm}$. 36. Fissitunicate ascus, bar $510 \mathrm{~mm}$. 37. Ascus in glycerin, bar $510 \mathrm{~mm}$. 38. Ascus in glycerin, bar $55 \mathrm{~mm}$. 39,40 . Ascospores mounted in water showing compressed gelatinous sheath and filamentous appendages, bars $520 \mathrm{~mm}$. 41. Ascospore in glycerin with sheath and appendages, bar $520 \mathrm{~mm}$. 42. Mature, brown three-septate ascospores, bar $520 \mathrm{~mm}$.

(E)-hexadec-9-en-1-ol as indicated for G155-1a (see Supplementary FIGs. 1, 2).

\section{Minutisphaera sp. G156-2}

FIGs. 30-42

Ascomata on wood, 160-200 mm high, 157-193 mm diam, black, superficial, scattered or in clusters, globose with a flattened top, which becomes collabent with age, apothecioid at maturity (FIGs. 30, 31). Beak absent. Dark hyphae-like structures present on upper ascoma wall in surface view (FIG. 32). Pseudoparaphyses 50-60 mm long, sparse, interspersed tightly among asci, branched or unbranched; tips of pseudoparaphyses enlarged $(1-3 \mathrm{~mm})$ and pigmented brown (F IGs. 33-35). Asci 57-70 3 15-23 mm numerous, broadly clavate, bitunicate, fissitunicate, rounded and thickened at the apex, sessile to short-stalked, with eight biseriate to triseriate ascospores (FIGs. 36-38). Ascospores 18-25 3 5-8 mm (av. 52237 mm, n 5 30), fusiform, multiguttulate, with a supra-median primary septum (0.31-0.41), upper hemisphere broader than lower hemisphere, slightly constricted at mid septum, rounded at the apex, tapering toward the base, hyaline, 
and one-septate when young, becoming brown and three-septate with age; surrounded by a gelatinous sheath ca. 1-3 $\mathrm{mm}$ wide at the ascospore base; sheath tightly adhered to the sides of the ascospore, with numerous filamentous appendages separating out of the sheath in water and radiating around the ascospore septum (FIGs. 39-42). Ascospores germinating from both apices.

Anamorph: None observed.

Cultural characters: Colonies on PDA attaining 21$25 \mathrm{~mm}$ diam within $25 \mathrm{~d}$ at $25 \mathrm{C}$ in light and dark, surface undulating and velvety, light brown to light gray.

Habitat: On submerged Pinus wood in a lake.

Known distribution: USA. North Carolina.

Specimen examined: USA North Carolina: Piedmont Plateau, Bur-Mil Park, Greensboro, Lake Brandt, 36.170556 N, $79.868333 \mathrm{~W}$, on submerged wood of Pinus sp., $27 \mathrm{Mar}$ 2012, H. Raja, G156-2.

Comments: Our collection of Minutisphaera sp. G156-2 resembles that of $M$. fimbriatispora in that it has black ascomata, the ascomata in surface view possess dark hyphae-like structures, asci are broadly clavate, and ascospores are one-septate (supra-median), multiguttulate, surrounded by a gelatinous sheath and bear numerous filamentous appendages that radiate around the mid-septum. The ascospores (18-25 $35-8 \mathrm{~mm})$ and asci (57-70 $315-23 \mathrm{~mm}$ ) of G156-2 however are smaller compared to those of $M$. fimbriatispora ( $\left.\mathrm{T}_{\mathrm{ABLE}} \mathrm{III}\right)$. On morphological grounds, we observed that G156-1 and G156-2 were quite similar in that they had smaller ascospores and asci, but there were minor size differences in their asci and ascospores ( $\mathrm{T}_{\mathrm{ABLE}} \mathrm{III}$ ).

Based on the ITS data, Minutisphaera sp. (G156-2) occurs on a separate clade (D) with 100\% PHYML and RAxML BS (FIG. 2). The interspecific differences in ITS sequences of the two isolates of G156-2 differed by $4-7 \%$ among the ITS strains of Minutisphaera spp. included in the analysis. Therefore, it is likely that G156-2 is a distinct species from among the strains included in the analyses. At present, however, we retain G156-2 as Minutisphaera sp. until we obtain and examine the morphology of additional collections as well as generate ITS and/or MCM7 sequences from different populations to examine intraspecific and interspecific relationships among strains of Minutisphaera spp. (G 156).

\section{DisCUSSION}

Ordinal placement of Minutisphaera clade within the Dothideomycetes. - BLAST analysis (Altschul et al. 1990) with other dothideomycete taxa in GenBank (Benson et al. 2012) suggest that the Minutisphaera fungi are close to Farlowiella carmichaeliana, a member of Hysteriaceae (Boehm et al. 2009a, b) or Pleosporomycetidae genera incertae sedis (Lumbsch and Huhndorf 2010). Based on phylogenetic analyses of combined SSU and LSU data, we could not determine the ordinal position of Minutisphaera spp. within the Dothideomycetes (FIG. 1). Farlowiella carmichaeliana forms a sister clade with Minutisphaera spp. with 98\% PHYML BS and 96\% RAxML BS (FIG. 1). Ferrer et al. (2011) also recovered high support for a clade including $F$. carmichaeliana and M. fimbriatispora in their ML analysis. Species in these genera can be distinguished easily by morphology of the ascomata (hysterothecial in Farlowiella vs. perithecioid or apothecioid in Minutisphaeria), although they share several characters, such as fissitunicate asci and one-septate ascospores.

Morphological characteristics, such as superficial apothecioid ascomata and pseudoparaphyses with enlarged tips that closely overarch the asci, were observed in M. japonica (FIGS. 3-21) as well as in the newly collected material of M. fimbriatispora and Minutisphaera sp. G156-2 from the USA (NC). These features are characteristic of the family Patellariaceae, Patellariales (Kutorga and Hawksworth 1997, Barr 2001).

To test the hypothesis that species of Minutisphaera might have phylogenetic affinities with members of the Patellariaceae within the Dothideomycetes, we included members of the Patellariaceae, such as Patellaria atrata (Hedw.) Fr., Hysteropatella clavispora (Peck) Höhn and H. elliptica (Fr.) Rehm (Boehm et al. 2009a), in the phylogenetic analyses of combined SSU and LSU data. We also included Catinella olivacea, a discomycetous fungus that grows on rotting logs. Catinella olivacea earlier was placed in the Leotiomycetes based on the morphology, but a more recent study by Greif et al. (2007) suggests that it is closely related to the Dothideomycetes, where it remains incertae sedis at the ordinal and familial rank. Results of the combined 83 taxa, two-gene (SSU + LSU) phylogeny suggested that the Minutisphaera clade did not share phylogenetic affinities with either members of Patellariaceae or C. olivacea (FIG. 1). This suggests that, thus far, the Minutisphaera clade is unique within the Dothideomycetes. Additional studies will be necessary with inclusion of taxa that belong to members of the Patellariaceae, which currently are heavily under represented in GenBank, before a new family can be proposed for this unique freshwater fungal clade.

Comparison of Minutisphaera spp. to morphologically similar taxa.-Minutisphaera japonica is similar to Karschia lignyota (Fr.) Sacc (Hafellner and Grazm 1976); it has flat, stalkless, olive-black ascomata, 
cylindrical-clavate, melanized ascospores, asci with thickened apices, pseudoparaphyses that produce a brownish gel, and fruits on damp, rotten wood. Minutisphaera japonica, however, differs from $K$. lignyota in having larger asci (55-82.5 3 21.5$32.5 \mathrm{~mm}$ vs. 35-45 $38-11 \mathrm{~mm}$ in $K$. lignyota) and ascospores (25-33 3 9-11 $\mathrm{mm}$ vs. 10-12 3 3-4 $\mathrm{mm}$ in $K$. lignyota). In addition, a gelatinous sheath surrounds ascospores of $M$. japonica, a character not reported for $K$. lignyota. The two taxa also differ in their habitat; $M$. japonica was found in submerged wood in a river in Japan, whereas, K. lignyota occurs in a terrestrial habitat.

Minutisphaera japonica is also morphologically similar to Dactylospora haliotrepha (Kohlm. \& Kohlm.) Hafellner on mangrove (Hafellner 1979) in having an apothecioid ascoma, pseudoparaphyses with an enlarged tip, bitunicate asci, and one-septate brown ascospores. Dactylospora haliotrepha was assigned previously to Buellia haliotrepha Kohlm. \& Kohlm. (Kohlmeyer and Kohlmeyer 1965) but later transferred to a novel genus Kymadiscus Kohlm. \& Kohlm. The two taxa are quite different, however: $M$. japonica has ascospores that are smooth-walled and surrounded by a gelatinous sheath, whereas those of $D$. haliotrepha have delicate longitudinal septa on the episporium wall and no sheath. Dactylospora haliotrepha shares phylogenetic affinities with the subclass Chaetothyriomycetidae of the Eurotiomycetes (Rossman et al. 2010), whereas based on a PHYML analysis of $M$. japonica with taxa in the Chaetothyriomycetidae, M.japonica shows no phylogenetic affinities with D. haliotrepha (data not shown).

Minutisphaera fimbriatispora should be compared to Banhegyia setispora Zeller \& Tóth, (Patellariales, Patellariaceae), which originally was described by Naoumoff (1915) for a collection on the bark of Juniperus communis L. in the Ural Mountains as Celidium proximellum (Nyl.) Karst. var. uralensis Naoumoff. Subsequently Zeller and Tóth (1960) collected the same fungus in the Hungarian Bükk Mountains and described it as a novel genus and species. Recent literature on B. setispora can be found in Kohlmeyer and Kohlmeyer (1979) and Jones et al. (2009). Minutisphaera fimbriatispora and $B$. setispora are morphologically similar in that they have apothecioid ascomata, clavate asci, and one-septate, hyaline to brown ascospores with appendages. They differ, however in that ascospores of $M$. fimbriatispora are surrounded by a gelatinous sheath and bear appendages radiating out of the mid-septum; those of $B$. setispora are polar. Although $B$. setispora is currently placed in the Patellariaceae, no molecular data are currently available to support its inclusion in the family or the order Patellariales.

Chemical analysis of organic extracts of both $M$. fimbriatispora (G155-1a) and Minutisphaera sp. (G156-1) revealed the presence of the polyunsaturated palmitic acid and (E)-hexadec-9-en-1-ol as the major components of the extracts. Shaw (1966) reviewed the polyunsaturated fatty acid composition of microorganisms, especially fungi, and related this to phylogeny. Stahl and Klug (1996) were able to characterize and differentiate fungi based on their fatty acid profiles. More recently, Spribille et al. (2011) used fatty acid profiles to reveal cryptic species in Mycoblastaceae, a lineage of lichenized Ascomycota. However, our chemical results suggest that the two distinctive species have similar polyunsaturated acids, but further analyses of the secondary metabolic content from additional strains will be required to define the variation in chemical profiles across the Minutisphaera clade.

The Minutisphaera clade ( $\mathrm{F}_{\mathrm{IG}}$. 1), which consists entirely of taxa described and reported from freshwater, remains unique within the Dothideomycetes, although morphological characteristics within this clade suggest that they may share putative phylogenetic affinities with members of the Patellariales (such as Banhegyia setispora and Karschia lignyota) for which sequence data are not currently available in GenBank.

\section{ACKNOWLEDGMENTS}

We thank Scott Jarmusch for his assistance with gas chromatography-mass spectrometry. The authors from the University of North Carolina were supported in part by internal research and development funds. Financial support by the Japan Society for the Promotion of Science (JSPS, 22770074) is gratefully acknowledged. Financial support from the National Science Foundation (NSF Grant No. 0844722 ) is greatly appreciated. Any opinions, findings and conclusions or recommendations expressed in this publication are those of the authors and do not necessarily reflect the views of the National Science Foundation.

\section{LITERATURE CITED}

Altschul SF, Gish W, Miller W, Myers EW, Lipman D. 1990. Basic local alignment search tool. J Mol Biol 215:403410.

Babushok VI, Linstrom PJ, Reed JJ, Zenkevich IG, Brown RL, Mallard WG, Stein SE. 2007. Development of a database of gas chromatographic retention properties of organic compounds. J Chromatogr A 1157:414-421, doi:10.1016/j.chroma.2007.05.044 
Barr ME. 2001. Ascomycota. In: McLaughlin DJ, Mc-Laughlin EG, Lemke PJ, eds. The Mycota VII, Part A. New York: Springer-Verlag. p 161-177.

Benson DA, Karsch-Mizrachi I, Clark K, Lipman DJ, Ostell J, Sayers EW. 2012. GenBank. Nucleic Acids Res 40:D48D53, doi:10.1093/nar/gkr1202

Boehm EWA, Mugambi G, Miller AN, Huhndorf SM, Marincowitz S, Spatafora JW, Schoch CL. 2009a. A molecular phylogenetic reappraisal of the Hysteriaceae, Mytilinidiaceae and Gloniaceae (Pleosporomycetidae, Dothideomycetes, Ascomycota), with keys to world species. Stud Mycol 64:49-83, doi:10.3114/ $\operatorname{sim} .2009 .64 .03$

-, Schoch CL, Spatafora JW. 2009b. On the evolution of the Hysteriaceae and Mytilinidiaceae (Pleosporomycetidae, Dothideomycetes, Ascomycota) using four nuclear genes. Mycol Res 113:461-479, doi:10.1016/ j.mycres.2008.12.001

Boonmee S, Ko TWK, Chukeatirote E, Hyde KD, Chen H, Cai L, McKenzie EHC, Jones EBG, Kodsueb R, Hassan BA. 2012. Two new Kirschsteiniothelia species with a Dendryphiopsis anamorph cluster in Kirschsteiniotheliaceae fam. nov. Mycologia 104:698-714, doi:10.3852/ 11-089

Campbell J, Ferrer A, Raja HA, Sivichai S, Shearer CA. 2007. Phylogenetic relationships among taxa in the Jahnu- lales inferred from $18 \mathrm{~S}$ and $28 \mathrm{~S}$ nuclear ribosomal DNA sequences. Can J Bot 85:873-882, doi:10.1139/B07-080 Castresana J. 2000. Selection of conserved blocks from multiple alignments for their use in phylogenetic analysis. Mol Biol Evol 17:540-552, doi:10.1093/ oxfordjournals.molbev.a026334

Dictionary of natural products, The Chapman \& Hall/CRC Chemical Database (www.chemnetbase.com). [Accessed Apr 2012]

Felsenstein J. 1985. Confidence limits on phylogenies: an approach using bootstrap. Evolution 39:783-791, doi: $10.2307 / 2408678$

Ferrer A, Miller AN, Shearer CA. 2011. Minutisphaera and Natipusilla: two new genera of freshwater Dothideomycetes. Mycologia 103:411-423, doi:10.3852/10-177

Gardes M, Bruns TD. 1993. ITS primers with enhanced specificity for basidiomycetes - application to the identification of mycorrhizae and rusts. Mol Ecol 2:113-118, doi:10.1111/j.1365-294X.1993.tb00005.x

Greif MD, Gibas FC, Tsuneda A, Currah R. 2007. Ascoma development and phylogeny of an apothecoid Dothideomycete, Catinella olivacea. Am J Bot 94:1890-1899, doi:10.3732/ajb.94.11.1890

Guindon S, Gascuel O. 2003. A simple, fast and accurate algorithm to estimate large phylogenies by maximum likelihood. Syst Biol 52: 696- 704, doi:10.1080/ 10635150390235520

Hafellner J. 1979. Karschia. Revision einer Sammelgattung an der Grenze von lichenisierten und nichtlichenisierten Ascomyceten. Beih. Nova Hedwigia 62:1-248.

_, Grazm JP. 1976. Die Gattung Karschia - Bindeglied zwischen bitunicaten Ascomyceten und lecanoralen Flechtenpilzen? Plant Syst Evol 126:243-254, doi:10. 1007/BF00983364
Hillis DM, Bull JJ. 1993. An empirical test of bootstrapping as a method for assessing confidence in phylogenetic analysis. Syst Biol 42:182-192.

Hirayama K, Tanaka K, Raja HA, Miller AN, Shearer CA. 2010. A molecular phylogenetic assessment of Massarina ingoldiana sensu lato. Mycologia 102:729-746, doi:10.3852/09-230

Huelsenbeck JP, Ronquist FR. 2001. MrBayes: Bayesian inference of phylogenetic trees. Biometrics 17:754-755.

- 2005. Bayesian analysis of molecular evolution using MrBayes. In: Nielsen R, ed. Statistical methods in molecular ecology. New York: Springer Publishing Co. p 186-226.

Inderbitzin P, Landvik S, Abdel-Wahab MA, Berbee ML. 2001. Aliquandostipitaceae, a new family for two new tropical ascomycetes with unusually wide hyphae and dimorphic ascomata. Am J Bot 88:52-61, doi:10.2307/2657126

Jones EBG, Sakayaroj J, Suetrong S, Somrithipol S, Pang KL. 2009. Classification of marine Ascomycota, anamorphic taxa and Basidiomycota. Fungal Divers 35:1-187.

Kohlmeyer J, Kohlmeyer E. 1965. New marine fungi from mangroves and trees along eroding shorelines. Nova Hedwigia 9:89-104.

- 1 1979. Marine mycology: the higher fungi. New York: Academic Press.

Kutorga E, Hawksworth DL. 1997. A reassessment of the genera referred to the family Patellariaceae (Ascomycota). Syst Ascomycetum 15:1-110.

Lumbsch HT, Huhndorf SM. 2010. Myconet Volume 14. Part 2. Notes on Ascomycete Systematics. Nos. 47515113. Fieldiana: Life and Earth Sc, NS 1:42-64.

Miller MA, Pfeiffer W, Schwartz T. 2010. Creating the CIPRES Science Gateway for inference of large phylogenetic trees. In: Proceedings of the Gateway Computing Environments Workshop (GCE), 14 Nov 2010, New Orleans. p 1-8.

Naoumoff N. 1915. Champignons de l'Oural I. Bull Soc Oural. Sci Nat 35:1-48.

Pang KL, Abdel-Wahab MA, Sivichai S, El-Sharouney HM, JonesEBG.2002.Jahnulales (Dothideomycetes, Ascomycota): a new order of lignicolous freshwater ascomycetes. Mycol Res 106:1031-1042, doi:10.1017/S095375620200638X

Posada D. 2008. jModeltest-phylogenetic model averaging. Mol Biol Evol 25:1253-1256, doi:10.1093/molbev/msn083

— - Buckley TR. 2004. Model selection and model averaging in phylogenetics: advantages of Akaike information criterion and Bayesian approaches over likelihood ratio tests. Syst Biol 53:793-808, doi:10.1080/ 10635150490522304

Raja HA, Miller AN, Shearer CA. 2012. Freshwater Ascomycetes: Natipusillaceae, a new family of tropical fungi, including Natipusilla bellaspora sp. nov. from the Peruvian Amazon. Mycologia 104:569-573, doi:10. 3852/11-150

—, Schoch CL, Hustad VP, Shearer CA, Miller AN. 2011a. Testing the phylogenetic utility of $M C M 7$ in the Ascomycota. Mycokeys 1:63-94, doi:10.3897/mycokeys. 1.1966

, Tanaka K, Hirayama K, Miller AN, Shearer CA. 2011b. Freshwater ascomycetes: two new species of 
Lindgomyces (Lindgomycetaceae, Pleosporales. Dothideomycetes) from Japan and USA. Mycologia 103: 1421-1432, doi:10.3852/11-077

Rayner RW. 1970. A mycological color chart. Commonwealth Mycological Institute Kew and British Mycological Society.

Rehner SA, Samuels GJ. 1994. Taxonomy and phylogeny of Gliocladium analyzed from nuclear large subunit ribosomal DNA sequences. Mycol Res 98:625-634, doi:10.1016/S0953-7562(09)80409-7

Rossman AY, Schoch CL, Farr DF, Nishijima K, Keith L, Goenaga. 2010. Dolabra nepheliae on rambutan and lychee represents a novel lineage of phytopathogenic Eurotiomycetes. Mycoscience 51:300-309, doi:10.1007/ s10267-010-0042-y

Schoch CL, Crous PW, Groenewald JZ, Boehm EWA, Burgess TI, de Gruyter J, de Hoog GS, Dixon LJ, Grube M, Gueidan C, Harada Y, Hatakeyama S, Hirayama K, Hosoya T, Huhndorf SM, Hyde KD, Jones EBG, Kohlmeyer J, Kruys Å, Li YM, Lücking R, Lumbsch HT, Marvanová L, Mbatchou JS, McVay AH, Miller AN, Mugambi GK, Muggia L, Nelsen MP, Nelson P, Owensby CA, Phillips AJL, Phonpaichit S, Pointing SB, PujadeRenaud V, Raja HA, Rivas Plata E, Robbertse B, Ruibal C, Sakayaroj J, Sano T, Selbmann L, Shearer CA, Shirouzu T, Slippers B, Suetrong S, Tanaka K, VolkmannKohlmeyer B, Wingfield MJ, Wood AR, Woudenberg JHC, Yonezawa H, Zhang Y, Spatafora JW. 2009. A classwide phylogenetic assessment of Dothideomycetes. Stud Mycol 64:1-15, doi:10.3114/sim.2009.64.01

Shaw R. 1966. The polyunsaturated fatty acids of microorganisms. In: Paoletti R, Kritchevsky D, eds. Advances in lipid research. Vol.4. New York: Academic Press.p 107174.

Shearer CA, Langsam DM, Longcore JE. 2004. Fungi in freshwater habitats. In: Mueller GM, Bills GF, Foster MS, eds. Biodiversity of fungi: inventory and monitoring methods. San Diego: Elsevier Academic Press. p 513-532.

—_ Raja HA. 2012. Freshwater Ascomycetes Database (http://fungi.life.illinois.edu/). [Accessed Apr 2012]

— - , Miller AN, Nelson P, Tanaka K, Hirayama K, Marvanova L, Hyde KD, Zhang Y. 2009. The molecular phylogeny of freshwater Dothideomycetes. Stud Mycol 64:145-153, doi:10.3114/sim.2009.64.08

Shoemaker RA. 1984. Canadian and some extralimital Nodulosphaeria and Entodesmium species. Can J Bot 62:2730-2753, doi:10.1139/b84-367

Spribille T, Klug B, Mayrhofer H. 2011. A phylogenetic analysis of the boreal lichen Mycoblastus sanguinarius (Mycoblastaceae, lichenized Ascomycota) reveals cryptic clades correlated with fatty acid profiles. Mol Phylogenet Evol 59:603-614, doi:10.1016/j.ympev.2011.03.021

Stahl PD, Klug MJ. 1996. Characterization and differentiation of filamentous fungi based on fatty acid composition. App Environ Microbiol 62:4136-4146.

Stamatakis A, Hoover P, Rougemont J. 2008. A rapid bootstrap algorithm for the RAxML web servers. Syst Biol 57:758-771, doi:10.1080/10635150802429642
Suetrong S, Boonuuen N, Pang K-L, Ueapattanakit J, Klaysuban A, Sri-indrasutdhi V, Sivichai S, Jones EBG. 2011. A taxonomic revision and phylogenetic reconstruction of the Jahnulales (Dothideomycetes) and the new family Manglicolaceae. Fungal Divers 51:163-188, doi:10.1007/ s13225-011-0138-5

, Schoch CL, Spatafora JW, Kohlmeyer B, VolkmannKohlmeyer J, Sakayaroj S, Phongpaichit K, Tanaka K, Hirayama K, Jones EBG. 2009. Molecular systematics of the marine Dothideomycetes. Stud Mycol 64:155-173, doi:10.3114/sim.2009.64.09

Swofford DL. 2002. PAUP* 4: phylogenetic analysis using parsimony (*and other methods). Sunderland, Massachusetts: Sinauer Associates.

Talavera G, Castresana J. 2007. Improvement of phylogenies after removing divergent and ambiguously aligned blocks from protein sequence alignments. Syst Biol 56:564-577, doi:10.1080/10635150701472164

Tanaka K, Harada Y. 2003. Pleosporales in Japan 1: the genus Lophiostoma. Mycoscience 44:85-96, doi:10. 1007/s10267-002-0085-9

, Hirayama K, Yonezawa H, Hatakeyama S, Harada Y, Sano T, Shirouzu T, Hosoya T. 2009. Molecular taxonomy of bambusicolous fungi: Tetraplosphaeriaceae, a new pleosporalean family with Tetraploa-like anamorphs. Stud Mycol 64:175-209, doi:10.3114/ $\operatorname{sim} .2009 .64 .10$

White TJ, Bruns T, Lee S, Taylor J. 1990. Amplification and direct sequencing of fungal ribosomal RNA genes for phylogenetics. In: Innis MA, Gelfand DH, Sninsky JS, White TJ, eds. PCR protocol: a guide to methods and applications. San Diego: Academic Press. p 315322.

Wiens JJ. 1998. Combining datasets with different phylogenetic histories. Syst Biol 47:568-581, doi:10.1080/ 106351598260581

Wu HX, Schoch CL, Boonmee S, Bahkali AH, Chomnunti P, Hyde KD. 2011. A reappraisal of Microthyriaceae. Fungal Divers 51:189-248, doi:10.1007/s13225-011-0143-8

Zeller L, Tóth S. 1960. Banhegyia, eine neue Gattung der Lecanorales. Sydowia 14:326-329.

Zhang Y, Jeewon R, Fournier J, Hyde KD. 2008. Multigene phylogeny and morphotaxonomy of Amniculicola lignicola: a novel freshwater fungus from France and its relationships to the Pleosporales. Mycol Res 112: 1186-1194, doi:10.1016/j.mycres.2008.04.004

—_ Fournier J, Crous PW, Pointing SB, Hyde KD. 2009a. Phylogenetic and morphological assessment of two new species of Amniculicola and their allies (Pleosporales). Persoonia 23:45-54, doi:10.3767/ 003158509X472187

-, Schoch CL, Fournier J, Crous PW, de Gruyter J, Woudenberg JHC, Hirayama K, Tanaka K, Pointing SB, Spatafora JW, Hyde KD. 2009b. Multilocus phylogeny of Pleosporales: a taxonomic, ecological and evolutionary re-evaluation. Stud Mycol 64:85-102, doi:10.3114/ $\operatorname{sim} .2009 .64 .04$

- Wang HK, Fournier J, Crous PW, Jeewon R, Pointing SB, Hyde KD. 2009c. Toward a phylogenetic clarification of Lophiostoma/Massarina and 
morphological similar genera in the Pleosporales. Fungal Divers 38:225-251.

, Crous PW, Schoch CL, Hyde KD. 2012. Pleosporales. Fungal Divers 53:1-221, doi:10.1007/s13225-011-0117-x
Zhao S, Shamoun SF. 2006. The effects of culture media, solid substrates and relative humidity on growth, sporulation and conidial discharge of Valdensinia heterodoxa. Mycol Res 110:1340-1346, doi:10.1016/j.mycres.2006.08.001 